\title{
Treating anaerobic effluents using forward osmosis for combined water purification
} and biogas production

Schneider, Carina; Rajmohan, Rajath Sathyadev; Zarebska, Agata; Tsapekos, Panagiotis; Hélix-Nielsen, Claus

Published in:

Science of the Total Environment

Link to article, DOI:

10.1016/j.scitotenv.2018.08.036

Publication date:

2019

Document Version

Peer reviewed version

Link back to DTU Orbit

Citation $(A P A)$ :

Schneider, C., Rajmohan, R. S., Zarebska, A., Tsapekos, P., \& Hélix-Nielsen, C. (2019). Treating anaerobic effluents using forward osmosis for combined water purification and biogas production. Science of the Total Environment, 647, 1021-1030. https://doi.org/10.1016/j.scitotenv.2018.08.036

\section{General rights}

Copyright and moral rights for the publications made accessible in the public portal are retained by the authors and/or other copyright owners and it is a condition of accessing publications that users recognise and abide by the legal requirements associated with these rights.

- Users may download and print one copy of any publication from the public portal for the purpose of private study or research.

- You may not further distribute the material or use it for any profit-making activity or commercial gain

- You may freely distribute the URL identifying the publication in the public portal 


\section{Treating anaerobic effluents using forward osmosis for combined water purification and biogas production}

Carina Schneider

Rajath Sathyadev Rajmohan

Agata Zarebska

Panagiotis Tsapekos

Claus Hélix-Nielsen ${ }^{\mathrm{a}, \mathrm{b}, *}$

clhe@env.dtu.dk

a Technical University of Denmark, Department of Environmental Engineering, Bygningstorvet, Building 115, 2800 Kgs. Lyngby, Denmark

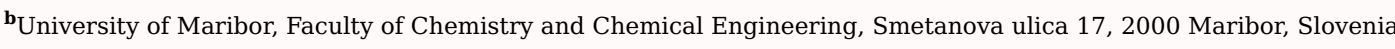

${ }^{*}$ Corresponding author at: Department of Environmental Engineering, Technical University of Denmark, Bygningstorvet Bygning 115, DK-2800 Kgs. Lyngby, Denmark.

Editor: Zhen (Jason) He

Abstract

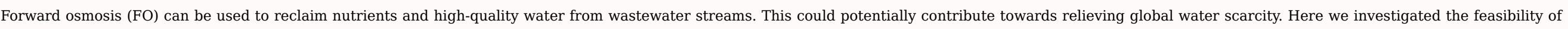

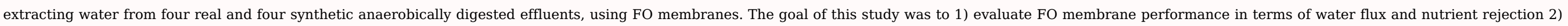

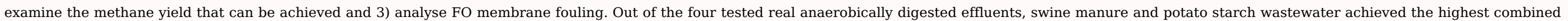

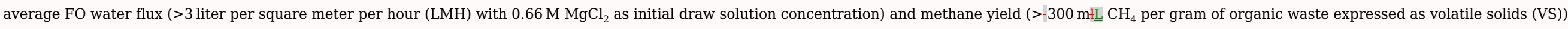

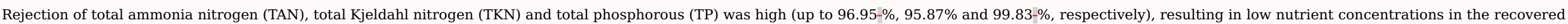

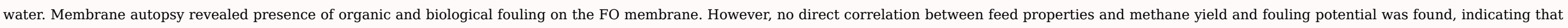
there is no inherent trade-off between high water flux and high methane production.

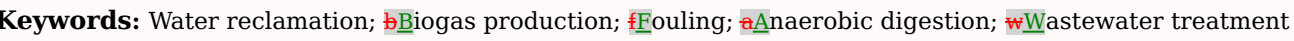

\subsection{Introduction}

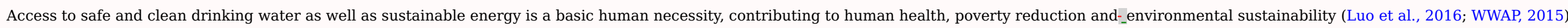

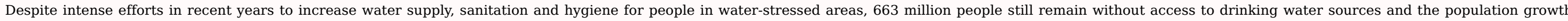

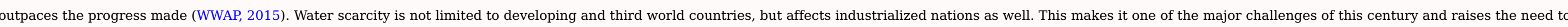
develop new sources of water (Shannon et al., 2008).

In addition, the quest to provide sustainable energy sources to satisfy a rapidly increasing global energy consumption while alleviating climate change has yet to be solved (McGinnis and Elimelech, 2008).

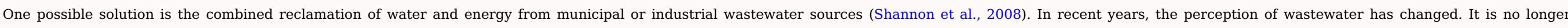
considered as waste, but a resource of nutrients (N, P and K), water and energy in form of biogas (Ansari et al., 2017; Lutchmiah et al., 2011).

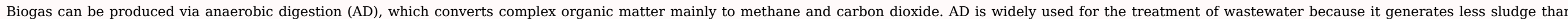




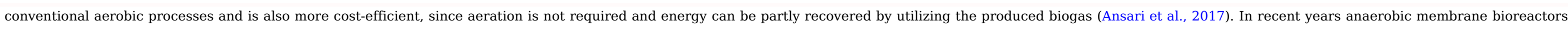

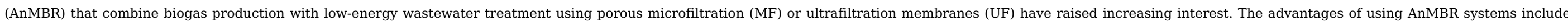
improved effluent quality, lower sludge production and improved biogas yields by increasing the retention time of anaerobic microorganisms in the bioreactor (Gu et al., 2015; Wang et al., 2017).

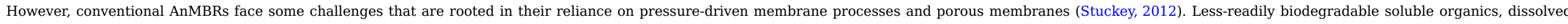

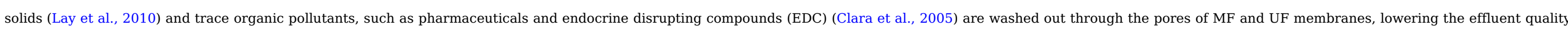

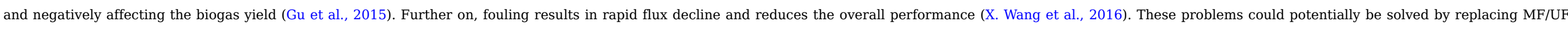
membranes with tight forward osmosis (FO) membranes.

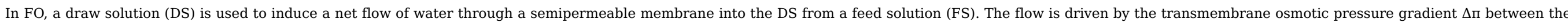

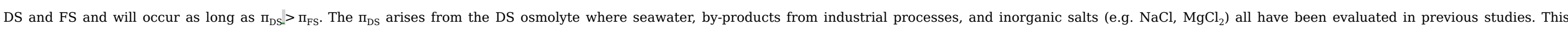

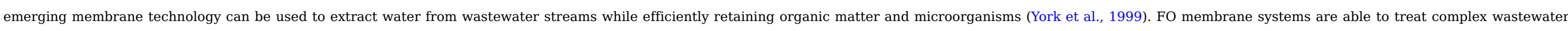

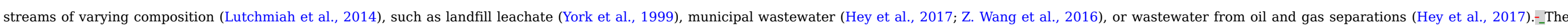
diluted DS from FO can be re-concentrated by reverse osmosis (RO) (Holloway et al., 2007) or membrane distillation (MD) (Liu et al., 2016), while simultaneously producing high quality water.

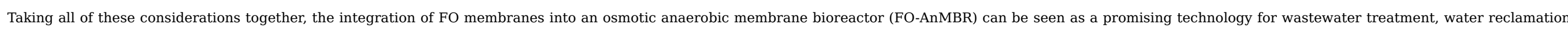

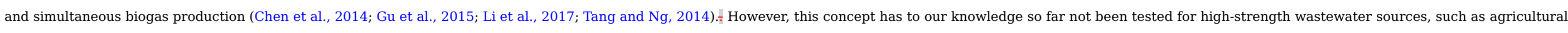
wastewater and cattle manure.

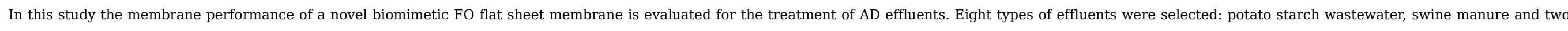

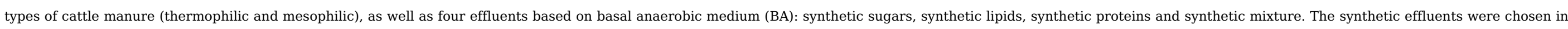
addition to the real effluents due to their known composition. This should help to find possible correlations between the effluent composition, biogas potential and fouling propensity.

The objective of the present study is to answer the following questions:

1) What is the FO membrane performance of the selected $\mathrm{AD}$ effluents, with regards to water flux and nutrient rejection?

2) What is the methane yield achieved by these wastewaters during $\mathrm{AD}$ ? This aspect is especially important with respects to reduction of operational expenditure.

3) What is the extent and the nature of the fouling and how does the composition of the AD effluents affect the membrane fouling?

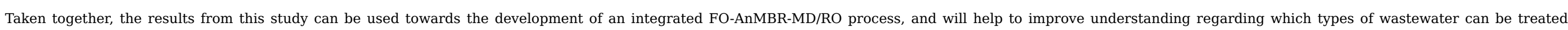
successfully, providing a compromise between high biogas production, good FO-based water extraction and low fouling potential. The scope of the article is depicted in Figure. 1. 


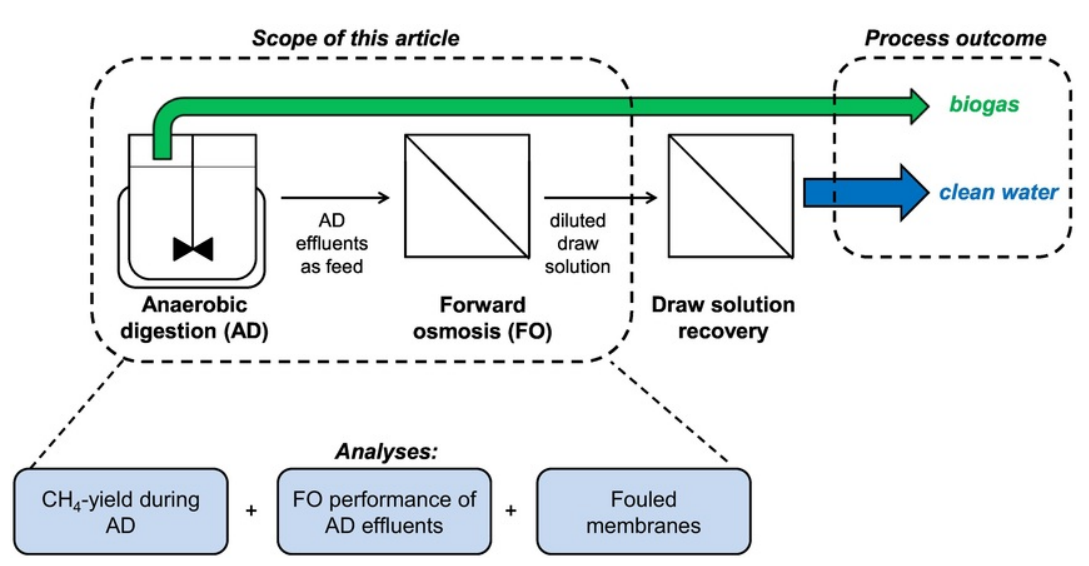

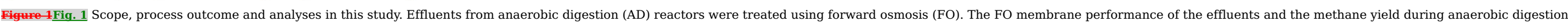
were evaluated. Furthermore, fouled membranes were analysed to gain insight into fouling properties_ alt-text: Fig. 1

\subsection{Material and methods}

\subsubsection{FO membrane}

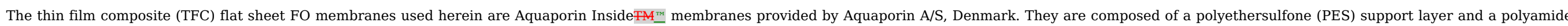

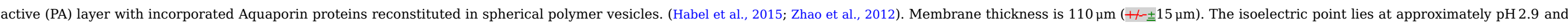
the zeta potential is between $=-80 \mathrm{mV}$ and $=-=90 \mathrm{mV}$ at $\mathrm{pH} 7$ (Singh et al., 2018).

\subsubsection{Anaerobic digestion effluents}

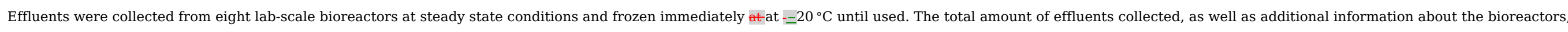

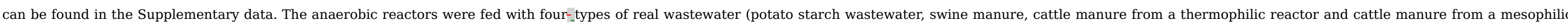

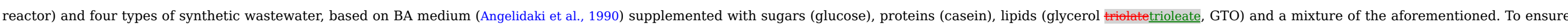

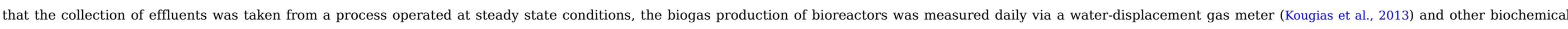

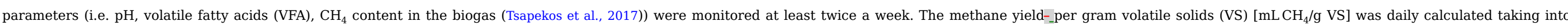
consideration the biogas production $[\mathrm{mL}]$, the organic loading rate (OLR) $[\mathrm{g} \mathrm{VS} / \mathrm{L}]$ and $\mathrm{CH}_{4}$ content $[\%]$ in the biogas:

methane yield $=\frac{\text { biogas production } * \mathrm{CH}_{4} \text { content }}{O L R * V_{L}}$

where $V_{L}$ is the reactor volume.

Further information about the bioreactors can be found in the Supplementary data and in previously published studies (Bassani et al., 2016; Mahdy et al., 2017; Tsapekos et al., 2017).

Prior to use, the effluents were unfrosted and sieved in three steps, using sieves with a mesh size of $1 \mathrm{~mm}, 250 \mu \mathrm{m}$ and $125 \mu \mathrm{m}$. The characteristics of the effluents are given in Table 1.

Table 1 Effluent characteristics.

alt-text: Table 1 


\begin{tabular}{|c|c|c|c|c|c|c|c|c|}
\hline & $\begin{array}{l}\text { Swine } \\
\text { manure }\end{array}$ & $\begin{array}{l}\text { Potato starch } \\
\text { wastewater }\end{array}$ & $\begin{array}{l}\text { Cattle manure, } \\
\text { thermophilic }\end{array}$ & $\begin{array}{l}\text { Cattle manure, } \\
\text { mesophilic }\end{array}$ & $\frac{\mathrm{BA}}{\text { medium + GTO }}$ & $\begin{array}{c}\text { BA } \\
\text { medium + glucose }\end{array}$ & $\begin{array}{c}\text { BA } \\
\text { medium }+ \text { mixture }\end{array}$ & $\begin{array}{c}\text { BA } \\
\text { medium + casein }\end{array}$ \\
\hline TOC [g/L] & $1.51 \_ \pm 0.01$ & $1.37 \_ \pm 0.12$ & $4.55 \_ \pm 0.00$ & $7.11 \_ \pm 0.05$ & $1.95 \pm \pm 0.15$ & $1.42 \pm 0.15$ & $1.18 \pm 0.01$ & $0.90 \_ \pm 0.48$ \\
\hline TS $[g / L]$ & $7.73 \pm 0.00$ & $8.68 \pm 0.35$ & $6.51 \pm \pm 3.18$ & $8.27 \pm 0.26$ & $7.06 \pm 0.02$ & $18.55 \pm 0.04$ & $6.72 \pm 0.30$ & $21.81 \pm 0.07$ \\
\hline VS [g/L] & $3.21 \_ \pm 0,33$ & $1.82 \_ \pm 11,57$ & $4.26 \_ \pm 2,84$ & $3.7 \pm 00,25$ & $3.53 \_ \pm 1,83$ & $10.91 \_ \pm 0,99$ & $4.15 \_ \pm 2,92$ & $15.14 \_ \pm 6,81$ \\
\hline TSS $[\mathrm{g} / \mathrm{L}]$ & $11.92 \pm 0.33$ & $13.70 \pm \_1.57$ & 23.17_士2.84 & $23.02 \pm 0.25$ & $21.03 \pm \pm 1.83$ & $14.12 \_0.99$ & 19.35_士2.92 & $12.79 \pm \pm 6.81$ \\
\hline TKN $[g / L]$ & $1.68 \_ \pm 0.01$ & $1.19 \_ \pm 0.09$ & $3.34 \pm 0.00$ & $2.20 \_ \pm 0.00$ & $5.97 \_ \pm 0.01$ & $4.84 \_ \pm 0.01$ & $3.80 \pm 0.00$ & $2.69 \_ \pm 0.32$ \\
\hline TAN $[g / L]$ & $2.08 \pm \pm 0.00$ & $0.91 \_ \pm 0.06$ & $3.41 \_ \pm 0.00$ & $1.66 \pm 0.00$ & $5.80 \_ \pm 0.00$ & $4.46 \pm 0.01$ & $3.24 \pm \pm 0.00$ & $1.79 \_ \pm 0.02$ \\
\hline Ortho-P [g/L] & $0.12 \_ \pm 0.00$ & $0.19 \_ \pm 0.06$ & $0.31 \_ \pm 0.00$ & $0.28 \_ \pm 0.01$ & $0.59 \_ \pm 0.00$ & $0.67 \_ \pm 0.00$ & $0.57 \_ \pm 0.00$ & $0.83 \pm \pm 0.00$ \\
\hline Density [kg/L] & $1.00 \_ \pm 0.00$ & $1.00 \_ \pm 0.00$ & $1.02 \_ \pm 0.00$ & $1.01 \pm \pm 0.00$ & $1.00 \pm \pm 0.00$ & $1.00 \pm 0.00$ & $1.00 \pm 0.00$ & $1.01 \_ \pm 0.00$ \\
\hline $\begin{array}{l}\text { Dynamic viscosity } \mu \\
\text { [mPa_s] }\end{array}$ & $1.35 \pm \pm 0.00$ & $1.15 \pm \pm 0.00$ & $2.00 \_ \pm 0.00$ & $\square_{-}$ & $1.39 \pm \pm 0.00$ & $1.44 \pm 0.00$ & $1.24 \pm \pm 0.00$ & $1.45 \pm \pm 0.00$ \\
\hline $\begin{array}{l}\text { Kinematic viscosity } \\
{\left[\mathrm{mm}^{2} / \mathrm{s}\right]}\end{array}$ & $1.35 \pm 0.00$ & $1.15 \pm 0.00$ & $2.00 \_ \pm 0.00$ & $-\Xi^{\mathrm{a}}$ & $1.37 \pm \pm 0.02$ & $1.44 \pm 0.00$ & $1.23 \_ \pm 0.02$ & $1.43 \pm \pm 0.00$ \\
\hline
\end{tabular}

a Viscosity could not be measured due to high TS content.

\subsubsection{Forward osmosis experimental setup}

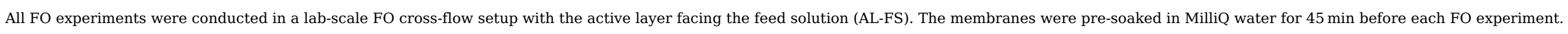

A schematic representation of the setup can be found in the Supplementary material.

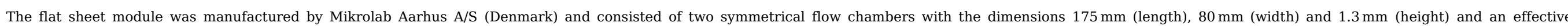
membrane area of $140 \mathrm{~cm}^{2}$.

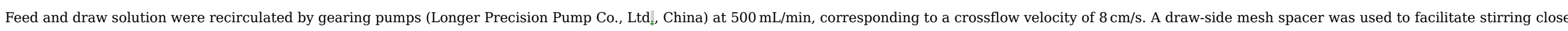
to the membrane surface.

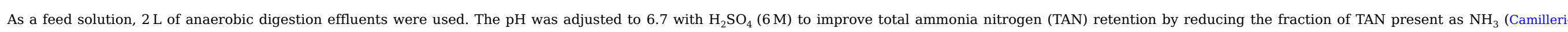
Rumbau et al., 2015). For the draw solution, $4 \mathrm{~L}$ of $0.66 \mathrm{M} \mathrm{MgCl}_{2}$ (analytical grade, Sigma--Aldrich, USA), was prepared by dissolving the salt in MilliQ water.

The concentration of the draw solute was chosen using the van Hoff equation for dilute and ideal solutions in order to yield a theoretical osmotic pressure of 49 bar.

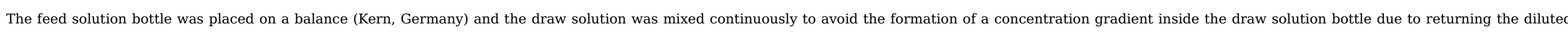
draw solution.

The water flux $J_{W}\left[\mathrm{~L} \mathrm{~m}^{-2}{ }^{2} \mathrm{~h}=1\right.$ ] was determined by recording the weight decrease of the feed solution, based on equationEq. (22)

$J w=\frac{\left(m_{t 2}-m_{t 1}\right)}{A_{m} \Delta t \rho}$

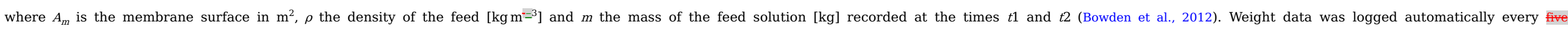
minutes 5 min throughout the entire duration of the experiments.

The concentration of the draw solution was not kept constant, meaning it decreased over time due to the water transport from feed to draw solution.

The reverse salt flux $J_{s}$ was calculated using equationEq. (3): 


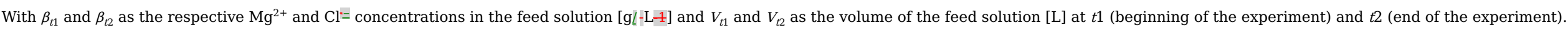

Nutrient rejection is calculated based on the feed side mass balance as

$R=\left(\frac{V_{t 1} c_{t 1}-V_{t 2} c_{t 2}}{V_{t 1} c_{t 1}}\right) \times 100 \%$

With $c_{t 2}$ and $c_{t 1}$ as the respective TAN, TN and TP= concentrations in the feed solution [mol $\mathrm{L}^{\mathrm{L}}=1$ ] at $t 1$ (beginning of the experiment) and $t 2$ (end of the experiment)!

The duration of the experiments was $24 \mathrm{~h}$ to allow formation of a fouling layer.

\subsubsection{Analytical methods}

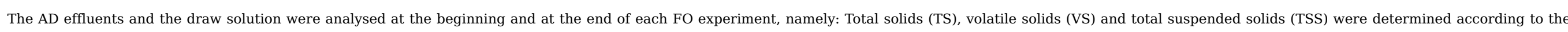

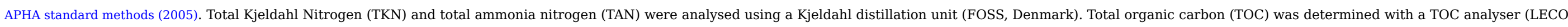

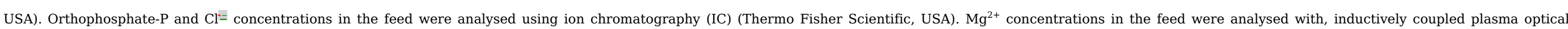
emission spectrometry (ICP-OES). Viscosity and density of the samples was measured using a viscosity meter (Anton Paar, Austria).

\subsubsection{Membrane autopsy for analysis of the fouled membrane}

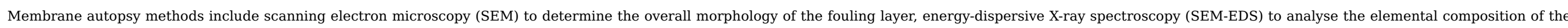

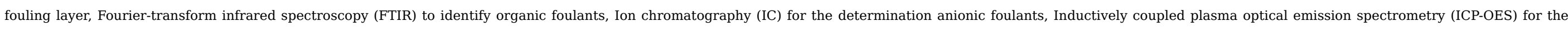
determination cationic foulants and Adenosine Triphosphate (ATP) analysis to analyse biological fouling

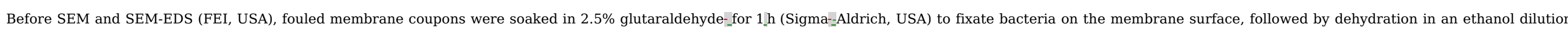

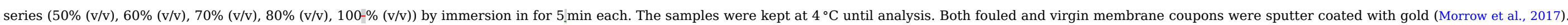
SEM samples were analysed at a $10 \mathrm{~mm}$ working distance, at an acceleration voltage of $10.0 \mathrm{kV}$ and a spot size of 3.0 .

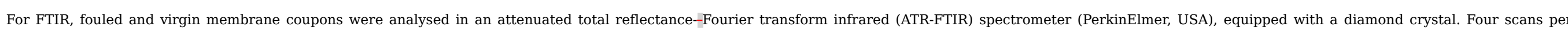
measurement point were collected.

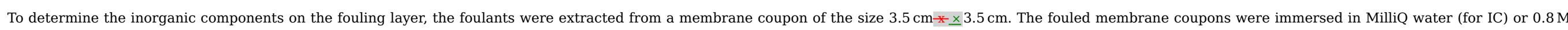

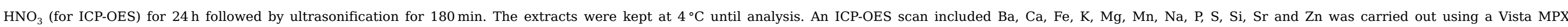
spectrometer (Varian, USA). IC analysis included chloride, bromide, nitrate and sulfate was analysed on a Thermoscientific DIONEX AS-AP (Thermo Fisher Scientific, USA).

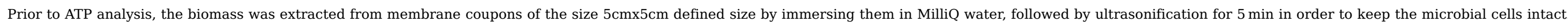

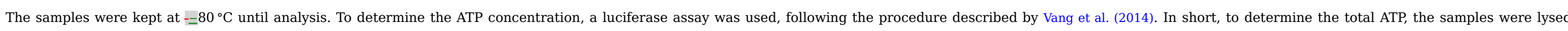

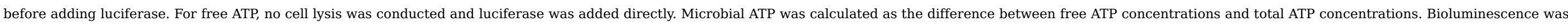
measured in a luminometer (Charles River, USA) and microbial ATP was determined indirectly by subtracting free (extracellular) ATP from total ATP.

\section{3. $\underline{3}$ Results and Đdiscussion}

\subsubsection{FO performance and methane yield of AD effluents}

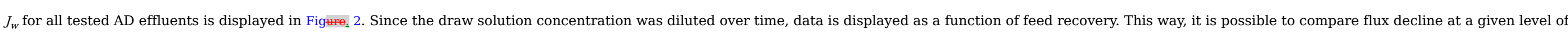
draw solution dilution (Blandin et al., 2016) The duration of the experiments was $24 \mathrm{~h}$ each. 


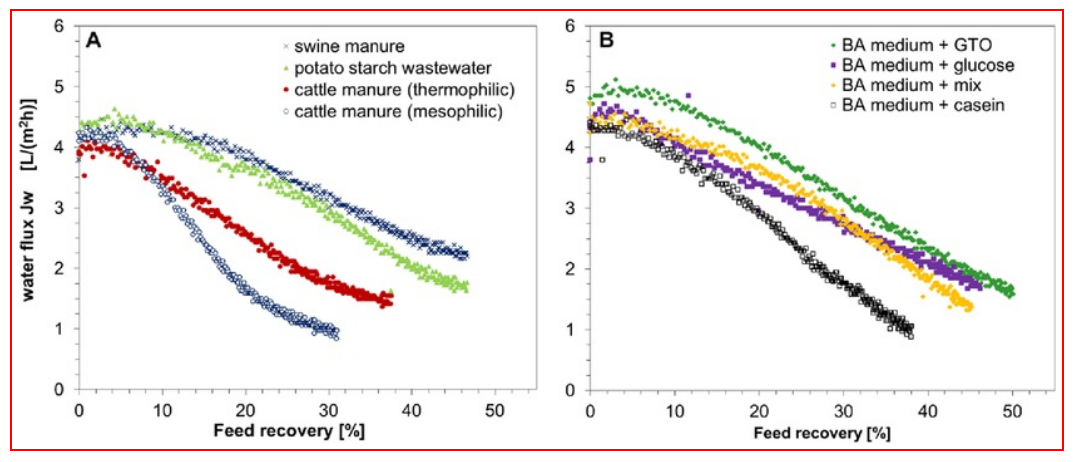

Figure 2Fiq. 2 Development of $J_{W}$ as a function of feed revory of anaerobic digestion effluents. Each sample point in the curves represents the mean value of two experiments $s_{-}$

alt-text: Fig. 2

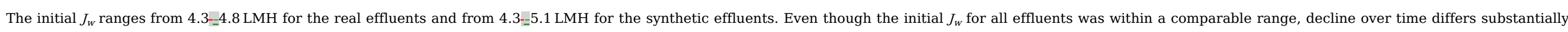

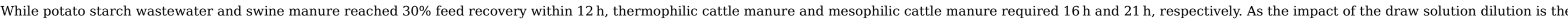

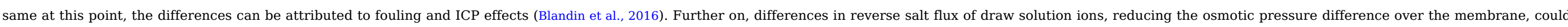
influence the results as well. However, there seems to be no direct correlation between flux decline and $J_{s, M g_{-}=}$or $J_{s, C l}$.

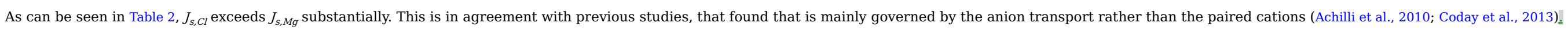

Table 2 FO performance. $J_{W}$, ave was calculated as a mean value of $J_{W}$, during the entire duration of the experiment. Flux decline is calculated over $24 \mathrm{~h}$.

\section{alt-text: Table 2}

\section{Real effluents}

Synthetic effluents

\begin{tabular}{|c|c|c|c|c|c|c|c|c|}
\hline & Swine manure & Potato starch wastewater & Cattle manure, thermophilic & Cattle manure, mesophilic & $\mathrm{BA}$ medium + GTO & BA medium + glucose & BA medium + mixture & BA medium + casein \\
\hline$J_{w: a v e}\left[\mathrm{~L} /\left(\mathrm{m}^{2} \mathrm{~h}\right)\right]$ & $3.3 \pm 0.10$ & $3.0 \pm \pm 0.22$ & $2.4 \pm \pm 0.01$ & $1.9 \pm 0.17$ & $3.1 \pm \pm 0.07$ & $2.9 \pm 0.38$ & $2.9 \pm 0.15$ & $2.4 \pm 0.63$ \\
\hline Flux decline [\%] & $40.67 \_ \pm \_10.37$ & $61.58 \pm 2.91$ & $59.92 \_ \pm 10.50$ & $76.16 \_ \pm 4.85$ & $66.12 \_ \pm 4.03$ & $56.09 \_ \pm 5.53$ & $71.03 \_ \pm 0.94$ & $74.88 \_ \pm \_19.81$ \\
\hline$J_{s, \uparrow g}\left[\mathrm{~g} /\left(\mathrm{m}^{2} \mathrm{~h}\right)\right]$ & $0.09 \_ \pm 0.02$ & $0.31 \_ \pm 0.06$ & $0.62 \_ \pm 0.02$ & $0.41 \_ \pm 0.05$ & $-=0.08 \pm \pm 0.00$ & $=0.10 \_ \pm 0.01$ & $0.10 \_ \pm 0.00$ & $0.01 \_ \pm 0.01$ \\
\hline$\left.J_{s, C l}\left[\mathrm{~g} /\left(\mathrm{m}^{2}\right] \mathrm{h}\right)\right]$ & $2.41 \pm \pm 1.02$ & $1.09 \_ \pm 0.06$ & $2.46 \pm \pm 0.15$ & $0.55 \pm \pm 0.26$ & $2.17 \_ \pm 0.42$ & $1.03 \_ \pm 0.78$ & $2.25 \_ \pm 1.50$ & $1.26 \pm \pm 1.24$ \\
\hline
\end{tabular}

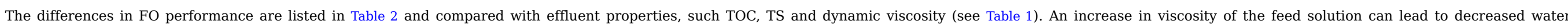
diffusivity over the membrane and thus decreased $J_{w}$ (McCutcheon and Elimelech, 2006; Phuntsho et al., 2012).

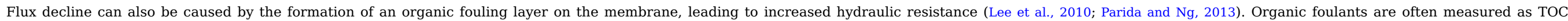
therefore the organic matter content of each tested effluents was assessed.

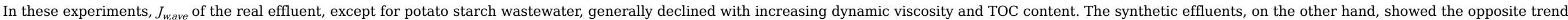

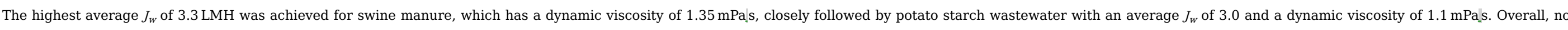
clear correlation between feed characteristics and FO performance was found.

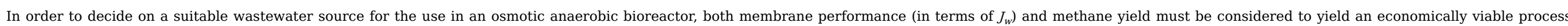

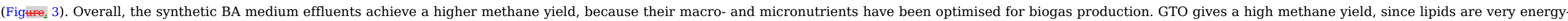




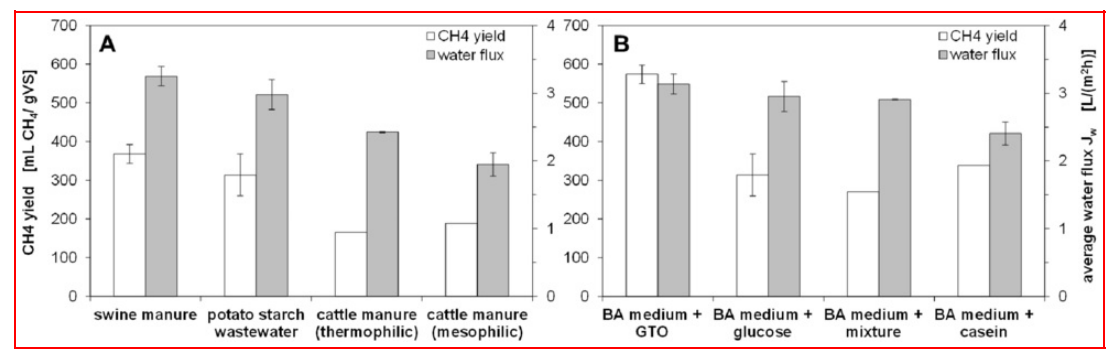

Figure 3Fiq. 3 Methane yield in comparison to the average $J_{W}$ over a time period of $24 . \mathrm{h}$.

\section{alt-text: Fig. 3}

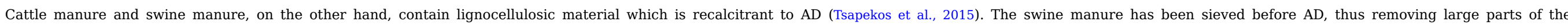

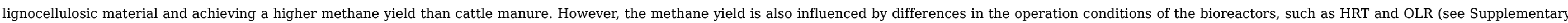
data).

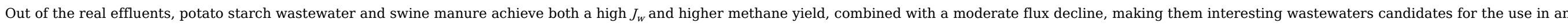

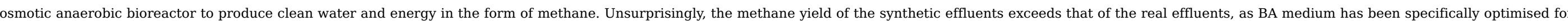
$\mathrm{AD}$.

\subsubsection{Nutrient rejection}

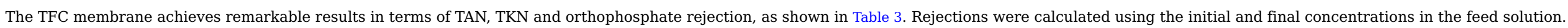

\section{Table 3 TAN, TKN and orthophosphate rejection.}

alt-text: Table 3

Rejection [\%]

TAN

\begin{tabular}{|l|}
\hline 92.34 \\
\hline 85.53 \\
\hline 96.95 \\
\hline 95.34 \\
\hline 81.25 \\
\hline 96.55 \\
\hline 80.76 \\
\hline 85.38 \\
\hline
\end{tabular}

Swine manure

Potato starch wastewater

Cattle manure, thermophilic

Cattle manure, mesophilic

$\mathrm{BA}$ medium + GTO

BA medium + glucose

BA medium + mixture

BA medium + casein

TKN

Orthophosphate-P

98.74

99.18

99.56

99.52

99.74

99.78

99.74

99.83

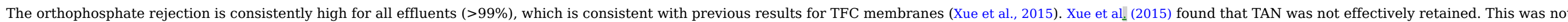

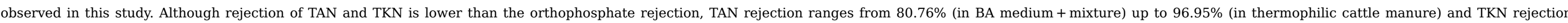

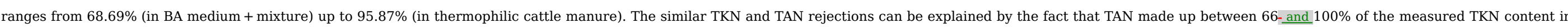




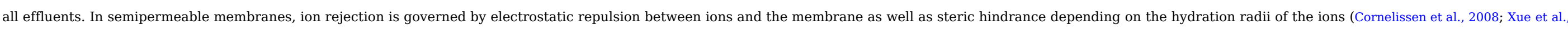

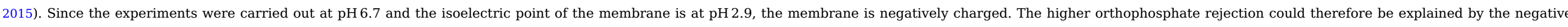

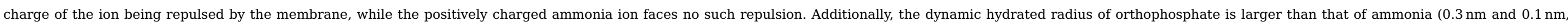
respectively) (Kiriukhin and Collins, 2002).

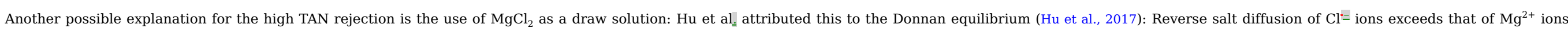

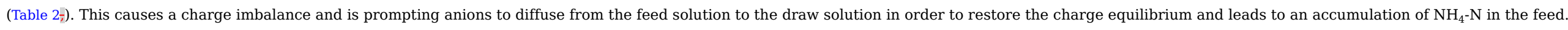

\subsubsection{Characterisation of FO fouling layer}

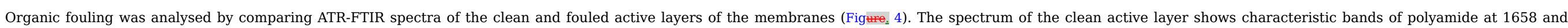
$1578 \mathrm{~cm}^{=1}$, which can be associated with amide I (C

O stretching) and amide II ( $\mathrm{N}$

H) respectively (Hey et al., 2016; Melián-Martel et al., 2012), whereas the bands at $1486 \mathrm{~cm}=1$ (CH3-

$\mathrm{C}-$

CH3 stretching), $\overline{1}-\mathbf{-} \mathrm{cm}^{-1}$ (C-

$\mathrm{SO}_{2-}$

C asymmetric stretching), $1298 \mathrm{~cm}^{=1}(\mathrm{~S}$

O stretching), $1242 \mathrm{~cm}^{=1}(\mathrm{C}-$

O-

C stretching), $1151 \mathrm{~cm}^{-1}{ }^{-1}(\mathrm{C}-$

$\mathrm{SO}_{2-}^{-}$

C symmetric stretching), as well as $1106 \mathrm{~cm}^{=1}$ and $872 \mathrm{~cm}^{=1}$ (skeletal aliphatic C-

C/aromatic hydrogen bending, rocking), $836 \mathrm{~cm}^{=1}$ and $719 \mathrm{~cm}^{=1}$ (aliphatic $\mathrm{C}$

H rocking) can be ascribed to the porous PES support layer, because the penetration depth samples both active and support layer (Singh et al., 2006).

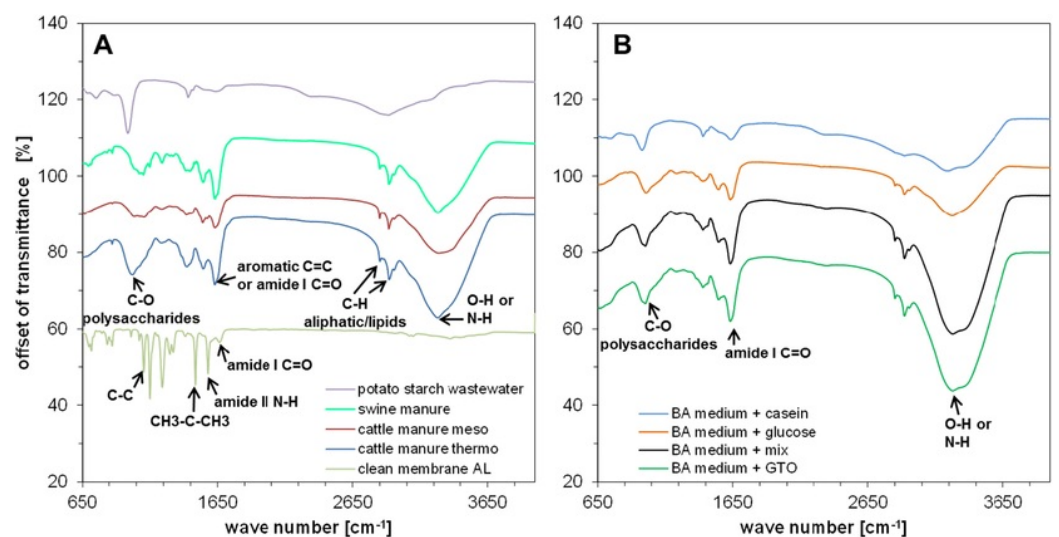




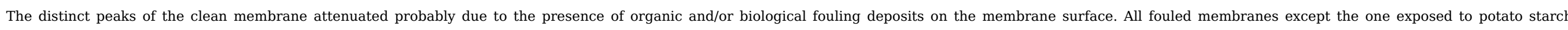
wastewater sample exhibit a broad, distinctive peak at $3241=3290 \mathrm{~cm}^{-1}$, which can be attributed to $\mathrm{O}$

$\mathrm{H}$ stretching of hydroxyl groups or $\mathrm{N}$

H stretching of amide A (Xu et al., 2016; Zarebska et al., 2014). The broadness of this peak suggests presence of polysaccharides, i.e. -

$\mathrm{CH}$ and -

OH groups.

Furthermore, there are smaller C

-

H peaks at 2917--2920 and 2847-_2858 cm=1. These peaks can be assigned to aliphatic compounds, lipids and aldehydes (Bell et al., 2017; Chang et al., 2011; Provenzano et al., 2014).

The peaks at $1627=1638 \mathrm{~cm}^{=1}=1$ is present in all fouled membrane samples and can be attributed to amide I C

O stretching vibrations, indicating the presence of proteins in the fouling layer (Bell et al., 2016; Hashim et al., 2010). Controversially, Bell and colleagues attributed a peak at $1625 \mathrm{Cm}^{=1}$ to a C

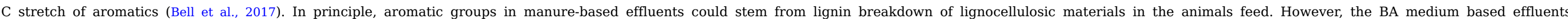
contain no lignin-based material, thus the band is likely to be associated with amide I.

The small peak at $1429=1432 \mathrm{~cm}^{=1}$ can be attributed to amide II $(\mathrm{N}$

H stretching), while another small peak at $981_{-=} 1022 \mathrm{~cm}^{=1}$ due to $\mathrm{C}$

O stretching corresponds to polysaccharides or polysaccharide-like substances (Chang et al., 2011; Melián-Martel et al., 2012; Provenzano et al., 2014).

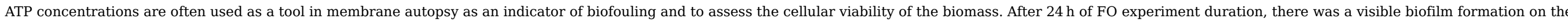

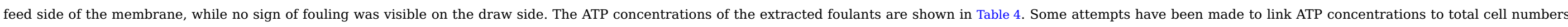

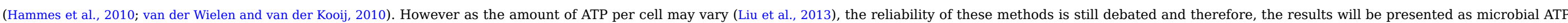
concentrations.

Table 4 ATP concentration of biomass extracted from membrane surface.

alt-text: Table 4

\begin{tabular}{|c|c|c|c|}
\hline & Total ATP & Free ATP & Microbial ATP \\
\hline & [ng] ATP/[ $\left[\mathrm{cm}^{2}\right]$ membrane & [ng] ATP/[ $\left.\mathrm{cm}^{2}\right]$ membrane & [ng] ATP/[ $\left.\mathrm{cm}^{2}\right]$ membrane \\
\hline Swine manure & $34.30 \pm 99.56$ & $1.08 \pm \pm 1.19$ & $33.22 \pm 8.37$ \\
\hline Potato starch wastewater & $1.40 \_ \pm 0.34$ & $0.13 \_ \pm 0.08$ & $1.46 \pm \pm 0.15$ \\
\hline Cattle manure (thermophilic) & $17.18 \_ \pm 11.56$ & $0.15 \pm \pm 0.02$ & $17.03 \_ \pm 11.54$ \\
\hline Cattle manure (mesophilic) & $6.54 \_ \pm 0.75$ & $0.70 \_ \pm 0.03$ & $5.84 \_ \pm 0.72$ \\
\hline BA medium + GTO & $149.96 \pm \pm 23.92$ & $1.11 \_ \pm 0.14$ & $148.85 \pm \pm 24.06$ \\
\hline BA medium + glucose & N/A & N/A & N/A \\
\hline BA medium + mixture & $10.52 \pm 0.47$ & $0.34 \_ \pm 0.21$ & $10.37 \_ \pm 0.96$ \\
\hline
\end{tabular}




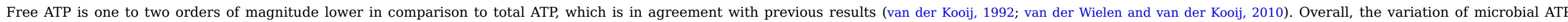

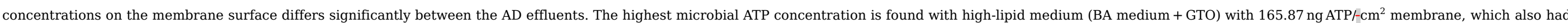

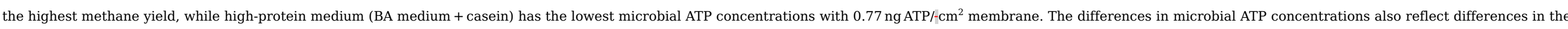

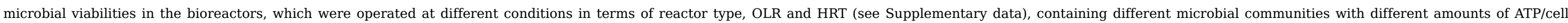
Furthermore, effluents were collected over a period of several weeks in order to have sufficient feed volumes, which may have affected the microbial viability as well.

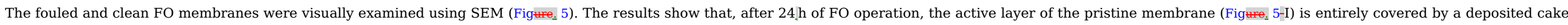
layer in all fouled samples, which as revealed by FTIR contains proteins and carbohydrates.
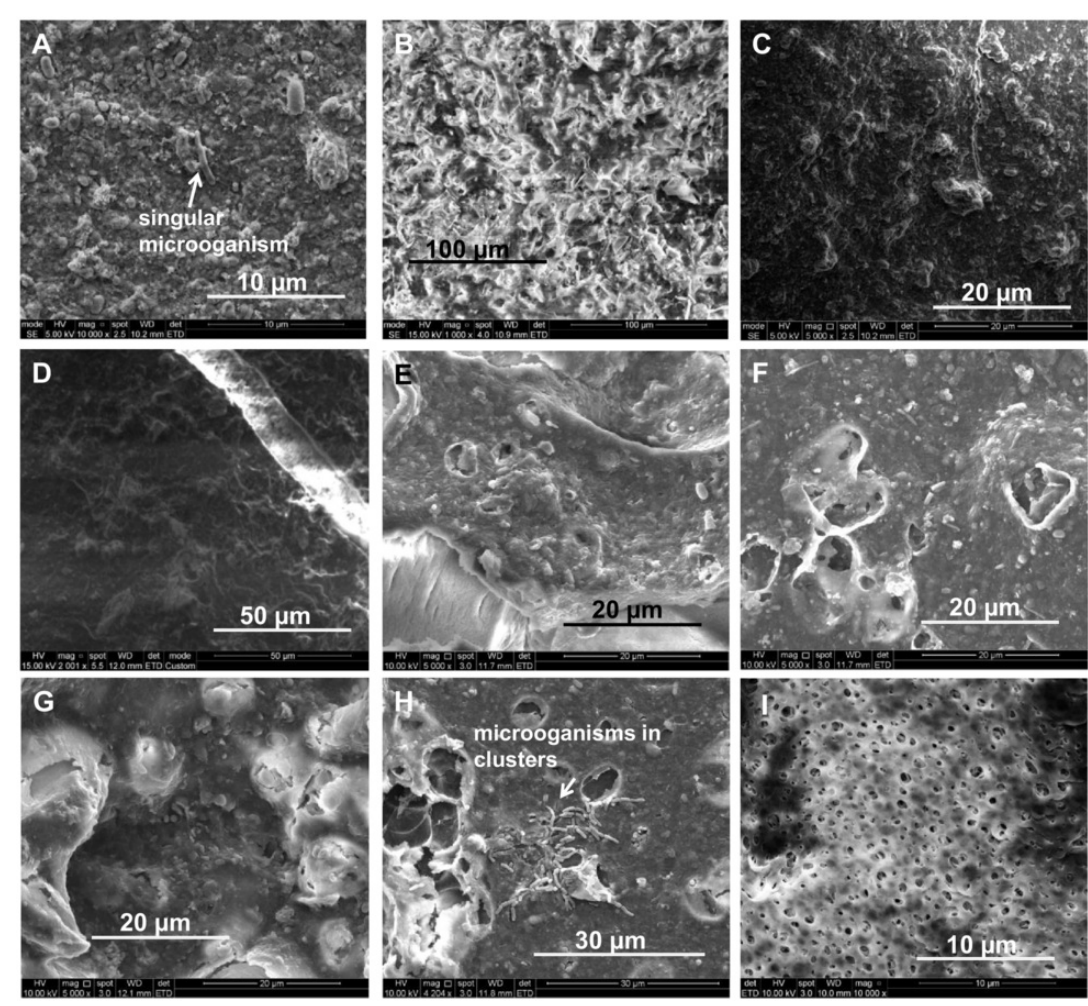

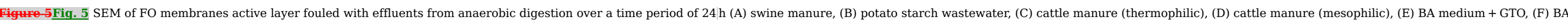
medium + casein, (G) BA medium + glucose, (H) BA medium + mix, (I) clean membrane (AL).

\section{alt-text: Fig. 5}

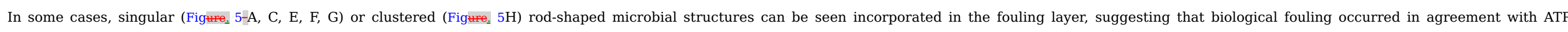

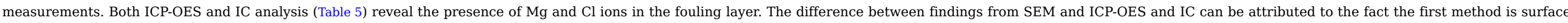

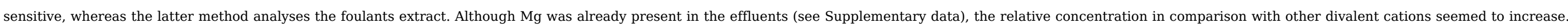

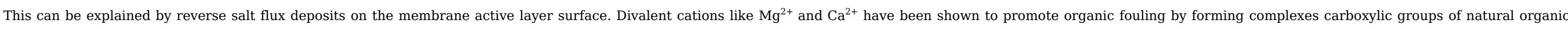
matter, thus helping to form intermolecular bridges (Mi and Elimelech, 2008). 


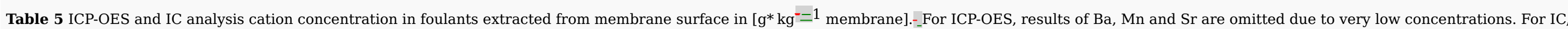
results for nitrate and bromide are not displayed, as they could not be detected in the samples.

\section{alt-text: Table 5}

\begin{tabular}{|c|c|c|c|c|c|c|c|c|c|}
\hline & $\begin{array}{l}\text { Concentration } \\
{\left[\mathrm{g}^{*} \mathrm{~kg}^{-=1}\right.} \\
\text { membrane] }\end{array}$ & $\begin{array}{l}\text { Swine } \\
\text { manure }\end{array}$ & $\begin{array}{l}\text { Potato starch } \\
\text { wastewater }\end{array}$ & $\begin{array}{l}\text { Cattle manure } \\
\text { (thermophilic) }\end{array}$ & $\begin{array}{l}\text { Cattle manure } \\
\text { (mesophilic) }\end{array}$ & $\begin{array}{c}\text { BA } \\
\text { medium + GTO }\end{array}$ & $\begin{array}{c}\text { BA } \\
\text { medium + glucose }\end{array}$ & $\begin{array}{c}\text { BA } \\
\text { medium }+ \text { mixture }\end{array}$ & $\begin{array}{c}\text { BA } \\
\text { medium }+ \text { casein }\end{array}$ \\
\hline \multirow{9}{*}{$\begin{array}{l}\text { ICP- } \\
\text { OES }\end{array}$} & $\mathrm{Ca}$ & $3.93 \_ \pm 2.62$ & $1.25 \pm \pm 1.08$ & $4.26 \pm \pm 0.06$ & $4.22 \pm 1.76$ & $2.84 \pm 0.86$ & $4.84 \_ \pm 2.11$ & $2.07 \pm 0.34$ & $2.08 \pm \pm 1.21$ \\
\hline & $\mathrm{Fe}$ & $0.76 \_ \pm 0.53$ & $0.18 \_ \pm 0.13$ & $0.45 \pm \pm 0.02$ & $0.44 \_ \pm \_0.24$ & $0.84 \_ \pm 0.13$ & $0.60 \pm 0.19$ & $0.35 \pm 0.04$ & $0.32 \pm 0.05$ \\
\hline & $\mathrm{K}$ & $2.97 \_ \pm 3.07$ & $13.62 \pm 0.52$ & $3.51 \_ \pm 0.98$ & $2.82 \pm \pm 1.51$ & $3.92 \_ \pm 1.72$ & $4.87 \_ \pm 1.93$ & $3.35 \pm \pm 2.14$ & $1.17 \pm \pm 0.62$ \\
\hline & $\mathrm{Mg}$ & $19.75 \pm \pm 20.44$ & $34.11 \pm 2.59$ & $12.82 \_ \pm 4.94$ & $9.3 \pm \pm 5.23$ & $36.04 \pm 10.32$ & $28.89 \_ \pm 8.37$ & $33.54 \pm 14.34$ & $32.52 \_ \pm 5.85$ \\
\hline & $\mathrm{Na}$ & $1.16 \_ \pm 1.20$ & $1.69 \_ \pm 0.18$ & $1.43 \_ \pm 0.36$ & $1.17 \pm 0.56$ & $1.75 \pm \pm 1.15$ & $2.87 \_ \pm 1.28$ & $2.18 \pm 1.69$ & $1.89 \_ \pm 1.56$ \\
\hline & $\mathrm{P}$ & $25.10 \pm \pm 27.72$ & $32.83 \_ \pm 13.58$ & $15.83 \pm 0.19$ & $11.46 \pm 8.83$ & $59.11 \pm 16.41$ & $32.40 \pm \pm 1.11$ & 33.13_士11.39 & $43.12 \pm 23.09$ \\
\hline & S & $2.59 \_ \pm 2.63$ & $2.91 \_ \pm 0.87$ & $0.62 \_ \pm 0.08$ & $0.56 \_ \pm 0.06$ & $1.05 \pm \pm 0.63$ & $2.12 \_ \pm 1.66$ & $1.71 \pm \pm 1.30$ & $2.75 \pm \pm 2.08$ \\
\hline & $\mathrm{Si}$ & $0.29 \_ \pm 0.19$ & $0.18 \_ \pm 0.04$ & $0.24 \_ \pm \_0.04$ & $0.22 \_ \pm 0.16$ & $0.30 \pm 0.06$ & $0.30 \_ \pm 0.11$ & $0.18 \pm 0.03$ & $0.12 \pm 0.06$ \\
\hline & $\mathrm{Zn}$ & $2.38 \_ \pm 1.57$ & $0.16 \pm \pm 0.10$ & $0.13 \pm \pm 0.03$ & $0.10 \_ \pm 0.09$ & $0.16 \pm 0.04$ & $0.16 \pm \pm 0.07$ & $0.11 \pm 0.01$ & $0.07 \_ \pm 0.04$ \\
\hline \multirow[t]{2}{*}{ IC } & $\mathrm{Cl}_{-}=$ & $2.97 \_ \pm 2.70$ & $5.19 \pm \pm 3.45$ & $7.97 \_ \pm 0.53$ & $5.37 \pm 0.22$ & $3.49 \pm 2.10$ & $3.65 \pm 0.01$ & $6.03 \pm 0.38$ & $4.96 \pm 0.24$ \\
\hline & $\mathrm{SO}_{4}{ }^{2}=$ & $0.14 \_ \pm 0.09$ & $0.15 \_ \pm 0.07$ & $1.07 \_ \pm \_0.08$ & $0.30 \_ \pm 0.04$ & $0.09 \pm \pm 0.05$ & $0.13 \pm \pm 0.05$ & $0.23 \pm 0.04$ & $0.43 \_ \pm 0.11$ \\
\hline
\end{tabular}

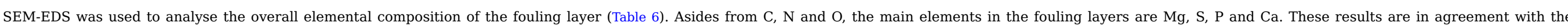

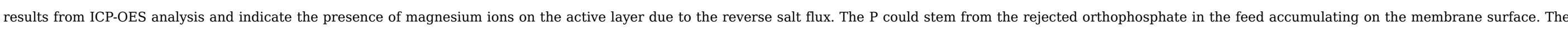
presence of $\mathrm{N}$ and $\mathrm{P}$ on the fouled membrane suggests biofouling and the presence of extracellular polymeric substances (EPS), which is confirmed by ATP analysis.

Table 6 Representative SEM-EDS results of FO membranes fouled with effluents from anaerobic digestion in weight \%.

\section{alt-text: Table 6}

\begin{tabular}{|c|c|c|c|c|c|c|c|c|}
\hline Weight \% & Swine manure & Potato starch wastewater & Cattle manure thermophilic & Cattle manure mesophilic & $\mathrm{BA}$ medium + GTO & BA medium + glucose & $\mathrm{BA}$ medium $+\operatorname{mix}$ & BA medium + casein \\
\hline C & & & 66.20 & 64.99 & 42.91 & 54.63 & 69.61 & 59.51 \\
\hline $\mathrm{N}$ & 12.83 & 11.89 & 7.42 & 7.11 & 0.91 & 4.85 & 6.67 & 5.49 \\
\hline $\mathrm{O}$ & 62.15 & 35.54 & 25.16 & 24.05 & 40.51 & 25.63 & 13.11 & 19.84 \\
\hline $\mathrm{Na}$ & & & & & & & & 0.09 \\
\hline $\mathrm{Mg}$ & 5.03 & 16.21 & 1.21 & 0.72 & 6.09 & 6.29 & 0.49 & 1.59 \\
\hline $\mathrm{Al}$ & 0.69 & & & 0.34 & & 0.09 & 0.14 & 0.59 \\
\hline $\mathrm{Si}$ & 1.73 & 1.14 & & 1.44 & & 0.15 & 0.41 & 2.48 \\
\hline$P$ & 4.89 & 20.80 & & 0.38 & 6.45 & 7.35 & 0.60 & 2.16 \\
\hline S & 2.11 & 5.48 & & 0.58 & 2.85 & 0.17 & 8.07 & 2.17 \\
\hline $\mathrm{K}$ & & 1.58 & & 0.05 & 0.11 & 0.09 & & 0.12 \\
\hline $\mathrm{Ca}$ & 5.74 & 1.98 & & 0.32 & 0.06 & 0.56 & 0.48 & 4.56 \\
\hline
\end{tabular}




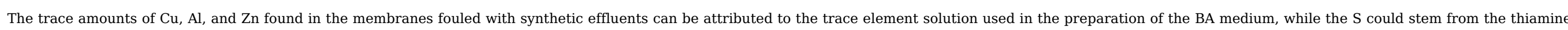
and thitiotictic acid in the vitamin solution (Angelidaki et al., 1990).

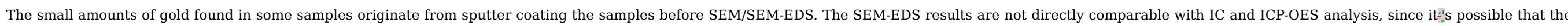
foulant layer composition is inconsistent over the membrane area. The complete SEM-EDS spectra can be found in the Supplementary data.

\section{4. $\underline{4}$ Conclusions}

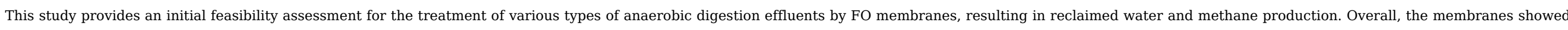
reasonable initial $J_{W}(4.3-=5.1 \mathrm{LMH})$ and high nutrient rejection, with TAN rejection ranging from 80.8-_97.0\% and orthophosphate rejection from 98.7--99.8\%

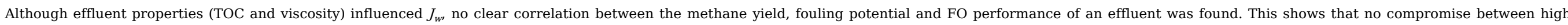
methane yield and $J_{w}$ has to be made, when choosing a wastewater candidate.

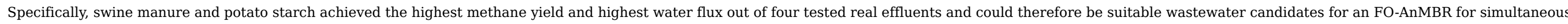
water purification and energy production.

During FO water extraction from anaerobic digested effluents the prevailing fouling is of biological and organic origin.

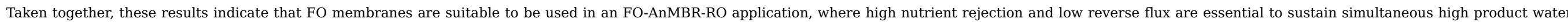

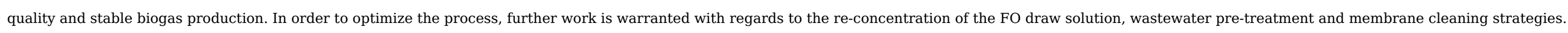

\section{Acknowledgements}

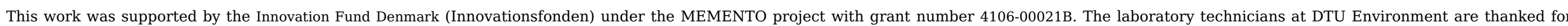
conducting the IC and ICP-OES analyses. The authors would further like to acknowledge the support from Aquaporin A/S for providing the FO membranes.

\section{Appendix A.Appendix A. Supplementary data}

Supplementary data to this article can be found online at https://doi.org/10.1016/j.scitotenv.2018.08.036.

\section{References}

Achilli A., Cath T.Y. and Childress A.E., Selection of inorganic-based draw solutions for forward osmosis applications, foumal of Membrime Sci. 364 (1), 2010, 233-241.

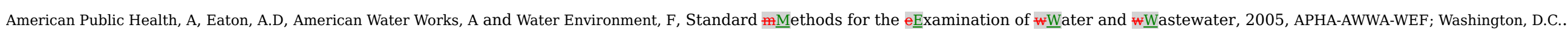

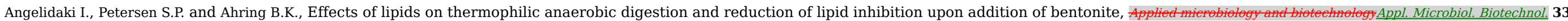

(4), 1990, 469-472.

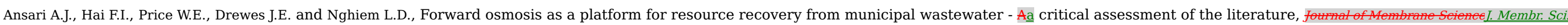
529, 2017, 195-206.

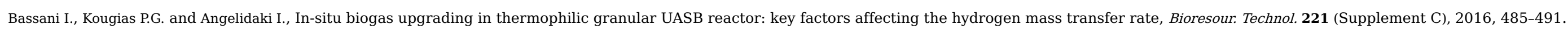

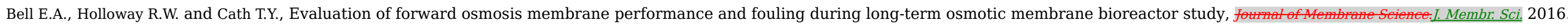




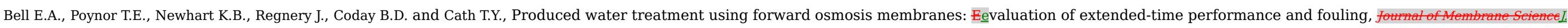
Membr. Sci. 525, 2017, 77-88.

Blandin G., Vervoort H., Le-Clech P. and Verliefde A.R.D., Fouling and cleaning of high permeability forward osmosis membranes, J. Water Process Eng. 9, 2016 , 161-169.

Bowden K.S., Achilli A. and Childress A.E., Organic ionic salt draw solutions for osmotic membrane bioreactors,

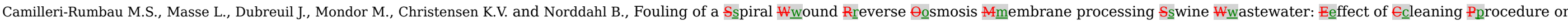
Ffouling Rresistance, Environ. Technol. 2015, 1-38, (just-accepted).

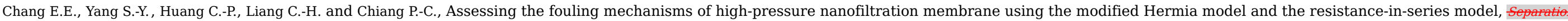
and Purification Technology Sep. Purif. Technol. 79 (3), 2011, 329-336.

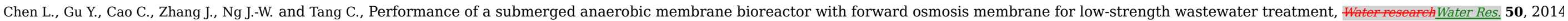
$114-123$.

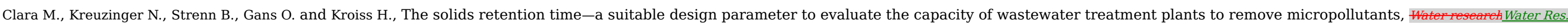
39 (1), 2005, 97-106.

Coday B.D., Heil D.M., Xu P. and Cath T.Y., Effects of transmembrane hydraulic pressure on performance of forward osmosis membranes, Environ. Sci. Technol. 47 (5), 2013 , $2386-2393$.

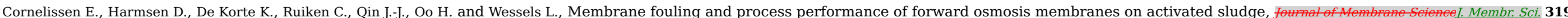
(1), 2008, 158-168.

van der Kooij D., Assimilable organic carbon as an indicator of bacterial regrowth, J. Am. Water Works Assoc. 1992, 57-65.

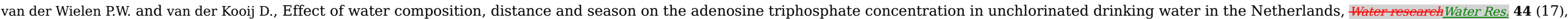
$2010,4860-4867$.

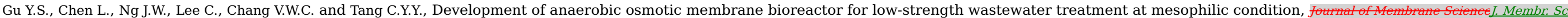
490, 2015, 197-208.

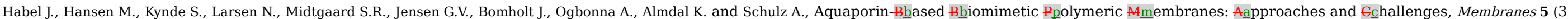
2015, 307-351.

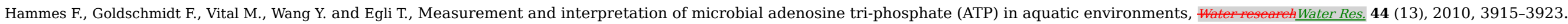

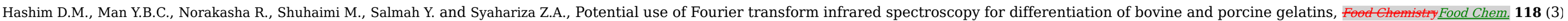
2010, 856-860.

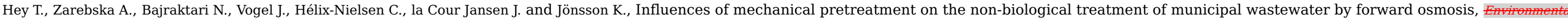
Environ. Technol. 2016, 1-10.

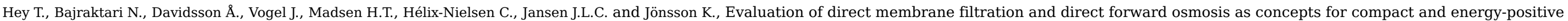
municipal wastewater treatment, Eniromental technol. 2017, 1-13.

Holloway R.W., Childress A.E., Dennett K.E. and Cath T.Y., Forward osmosis for concentration of anaerobic digester centrate,

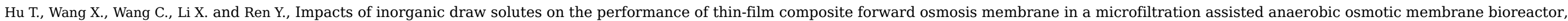


RSC AdveesSC Adv 7 (26), 2017, 16057-16063.

Kiriukhin M.Y. and Collins K.D., Dynamic hydration numbers for biologically important ions, Biophysical Chemistry Biophys. Chem. 99 (2), 2002, 155-168.

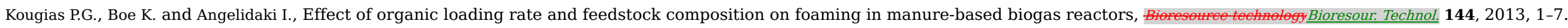

Lay W.C.L., Liu Y. and Fane A.G., Impacts of salinity on the performance of high retention membrane bioreactors for water reclamation: Aa review,

Lee S., Boo C., Elimelech M. and Hong S., Comparison of fouling behavior in forward osmosis (FO) and reverse osmosis (RO), fournal of Membrame Sciencel. Membr. Sci. 365 (1), 2010 , 34-39.

Li S., Kim Y., Phuntsho S., Chekli L., Shon H.K., Leiknes T. and Ghaffour N., Methane production in an anaerobic osmotic membrane bioreactor using forward osmosis: Eeffect of reverse salt flux, Technol. 239, 2017, 285-293.

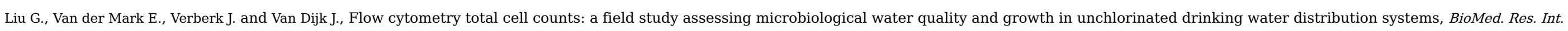
2013.

Liu Q., Liu C., Zhao L., Ma W., Liu H. and Ma J., Integrated forward osmosis-membrane distillation process for human urine treatment, Water researehWater Res. 91, 2016 , 45-54.

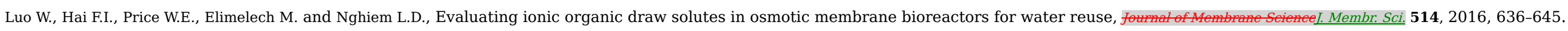

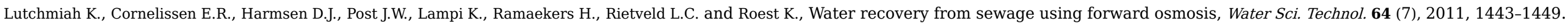

Lutchmiah K., Verliefde A., Roest K., Rietveld L.C. and Cornelissen E.R., Forward osmosis for application in wastewater treatment: a review, water researehWater Res. 58, $2014,179-197$.

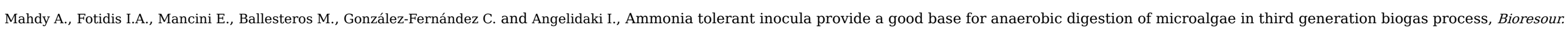
Technol. 225 (Supplement C), 2017, 272-278.

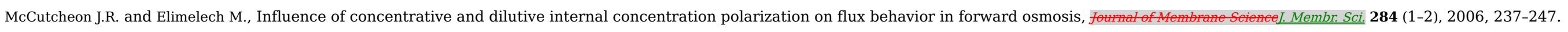

McGinnis R.L. and Elimelech M., Global challenges in energy and water supply: the promise of engineered osmosis, Environ. Sci. Technol. 42 (23), $2008,8625-8629$.

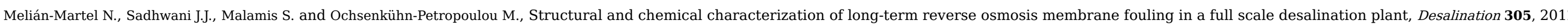
44-53.

Mi B. and Elimelech M., Chemical and physical aspects of organic fouling of forward osmosis membranes, fournal of Membrane SeienceJ. Membr. Sci. 320 (1), $2008,292-302$.

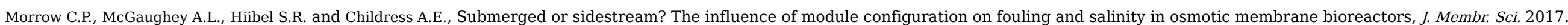

Parida V. and Ng H.Y., Forward osmosis organic fouling: Eeffects of organic loading, calcium and membrane orientation, Desalination 312, 2013, 88-98.

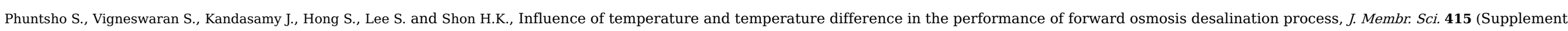
C), 2012, 734-744.

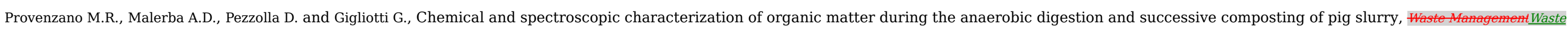
Manaq. 34 (3), 2014, 653-660.

Shannon M.A., Bohn P.W., Elimelech M., Georgiadis J.G., Marinas B.J. and Mayes A.M., Science and technology for water purification in the coming decades, Nature 452 (7185), 2008, 301-310.

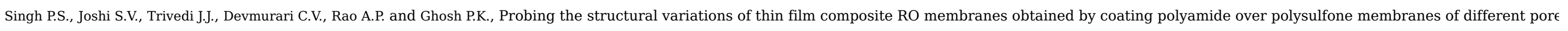
dimensions, Membr. Sci. 278 (1), 2006, 19-25.

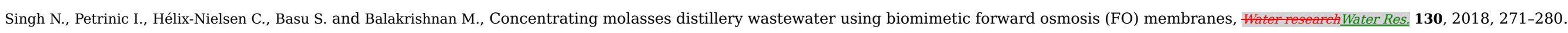


Stuckey D.C., Recent developments in anaerobic membrane reactors,

Tang M.K.Y. and Ng H.Y., Impacts of Different Draw Solutions on a Novel Anaerobic Forward Osmosis Membrane Bioreactor (AnFOMBR), 2014.

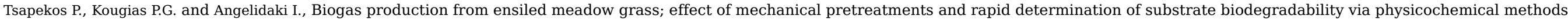
Biorestre Bioresour. Technol. 182, 2015, 329-335.

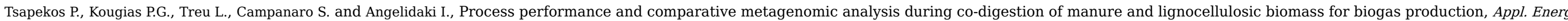
185 (Part 1), 2017, 126-135

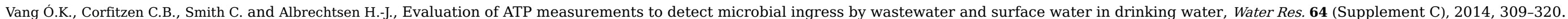

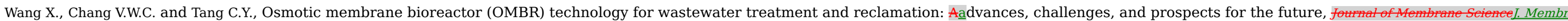
Sci. 504, 2016, 113-132.

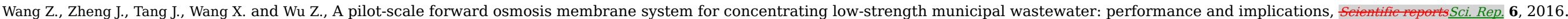

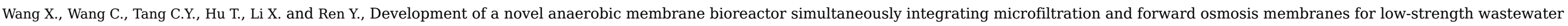
treatment, formal of Serimeel. Membr. Sci. 527, 2017, 1-7.

WWAP, The United Nations World Water Development Report 2015, 2015, Water for a Sustainable World; Paris.

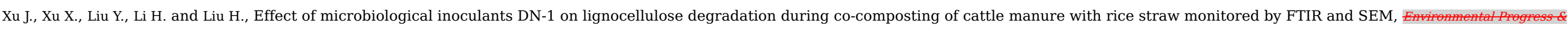
Sustainable Energy Environ. Prog. Sustain. Energy 35 (2), 2016, 345-351.

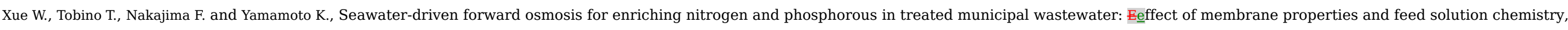
Water Res. 69, 2015, 120-130.

York R., Thiel R. and Beaudry E., Full-scale Experience of Direct Osmosis Concentration Applied to Leachate Management, 1999.

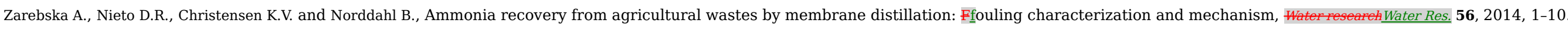

Zhao S., Zou L., Tang C.Y. and Mulcahy D., Recent developments in forward osmosis: opportunities and challenges, foumal of Membrane SeieneeJ. Membr. Sci. 396, 2012, 1-21.

\section{Appendix A.Appendix A. Supplementary data}

Multimedia Component 1

Supplementary material

alt-text: Image 1

\section{Graphical abstract}




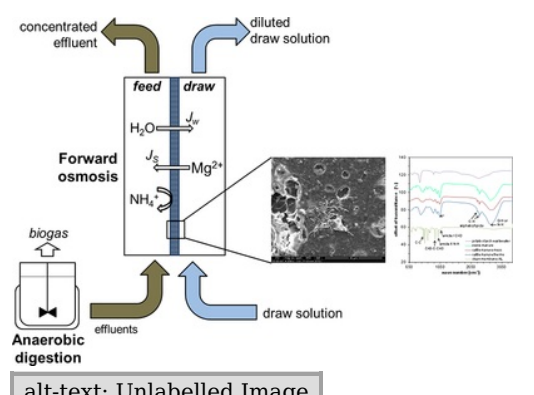

Highlights

- Biomimetic FO membranes extract water from anaerobic digestion effluents.

- The membranes achieve high ammonia and orthophosphate rejection.

- No trade-off between methane yield and water flux and fouling propensity.

- Organic fouling and biological fouling the active layer of the membrane.

\section{Queries and Answers}

Query:

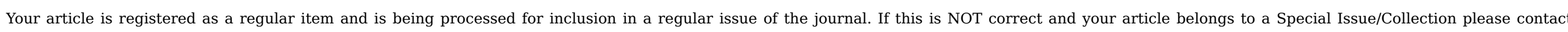
p.das@elsevier.com immediately prior to returning your corrections.

Answer: Yes

Query:

Please confirm that given names and surnames have been identified correctly and are presented in the desired order, and please carefully verify the spelling of all authors' names.

Answer: Yes

Query:

The author names have been tagged as given names and surnames (surnames are highlighted in teal color). Please confirm if they have been identified correctly

Answer: Yes

Query:

Please check whether the designated corresponding author is correct, and amend if necessary.

Answer: correct 
Query:

Have we correctly interpreted the following funding source(s) and country names you cited in your article: "Innovation Fund Denmark, Denmark".

\section{Answer: Yes}

Query:

Supplementary caption was not provided. Please check the suggested data if appropriate, and correct if necessary.

Answer: Please replace the supplementary material with the updated version attached

Attachments: supplementary material_06082018.docx

Query:

Please provide the volume number and page range for the bibliography in Bell et al., 2016.

Answer: Volume 517, Pages 1-13

Query:

Please provide the volume number and page range for the bibliography in Liu et al., 2013.

Answer: vol. 2013, Article ID 595872, 10 pages

Query:

Please provide the volume number and page range for the bibliography in Morrow et al., 2017.

Answer: Volume 548, Pages 583-592 